Original Article

\title{
Effects of modified Pilates on variability of inter-joint coordination during walking in the elderly
}

\author{
SuYeon Roh, PhD ${ }^{1)}$, Sukhoon Yoon, PhD ${ }^{2)}$, Joo Nyeon Kim, MS ${ }^{3)}$, Hee Sung Lim, PT, PhD 3)* $^{*}$ \\ 1) Department of Exercise Rehabilitation and Welfare, Gachon University, Republic of Korea \\ 2) Department of Community Sport, Korea National Sport University, Republic of Korea \\ 3) Department of Physical Education, Korea National Sport University: 1239 Yangjaedaero, \\ Songpa-gu, Seoul 138-763, Republic of Korea
}

\begin{abstract}
Purpose] This study aimed to examine the effects of an 8-week modified Pilates program on the variability of inter-joint coordination in the elderly during walking. [Subjects and Methods] Twenty elderly participants with no recent history of orthopedic abnormalities (age, $67.9 \pm 2.7$ years; height, $163.7 \pm 8.9 \mathrm{~cm}$; weight, $67.1 \pm$ $11.6 \mathrm{~kg}$ ) were recruited for this study and randomly allocated to a modified Pilates exercise group or a control group. Three-dimensional motion analysis was performed on both groups to evaluate the effects of the Pilates exercise. [Results] There was no significant difference in the joint variability of the ankle, knee, and hip joints between the groups, both before training and after training. However, there was a significant increase in the hip-knee deviation phase value in the exercise group after the program was completed, and this increase was also significant when compared with that in the control group. [Conclusion] This study has demonstrated that an 8-week modified Pilates exercise program can have a positive impact on the gait of elderly participants, potentially by enhancing neuromuscular adjustment, which may have positive implications for reducing their fall risk.

Key words: Elderly gait, Inter-joint coordinate variability, Pilates exercise
\end{abstract}

(This article was submitted Jul. 31, 2016, and was accepted Sep. 7, 2016)

\section{INTRODUCTION}

Pilates exercise is for making neutral spine position and involves various muscle exercises for improving muscular strength, endurance, and flexibility. It is known that the Pilates exercise has a positive effect on daily life, as it enhances balance and walking capabilities ${ }^{1-5}$. Since it can aid in the development of deep muscles such as the erector spinae, transverse abdominis, and internal oblique muscles, it has been frequently used as a rehabilitation exercise for stabilizing the spine and reducing back pain ${ }^{6,7)}$.

Recently, many researchers have utilized a modified form of Pilates exercise involving props for rehabilitation in the elderly and in patients with chronic stroke ${ }^{8-11)}$. It has been reported that this modified Pilates exercise is safe compared with ordinary Pilates exercise. The proper level of exercise can also be adjusted as required ${ }^{8-11)}$. Therefore, it can be useful for those with poor physical function and limited mobility, particularly as it can be done daily at home without the added difficulty of having to visit a rehabilitation center.

Bird and Fell ${ }^{12}$ ) reported that Pilates exercise with props enhanced both the knee extensor and the ankle dorsiflexor muscles in elderly participants. Other researchers have also reported that the improvement of muscular strength, muscle endurance, and flexibility in the trunk and the lower extremities resulting from performing Pilates exercise can enhance static/dynamic balance, which is required for gait in daily life and in particular, it has a positive effect on reducing the fall

\footnotetext{
*Corresponding author. Hee Sung Lim (E-mail: hslim2002@hotmail.com)

(C)2016 The Society of Physical Therapy Science. Published by IPEC Inc.

This is an open-access article distributed under the terms of the Creative Commons Attribution Non-Commercial No Derivatives (by-nc-nd) License $<$ http://creativecommons.org/licenses/by-nc-nd/4.0/>.
} 
Table 1. General characteristics of the subjects $(\mathrm{n}=20)$

\begin{tabular}{lcc}
\hline & Training group $(\mathrm{n}=10)$ & Control group $(\mathrm{n}=10)$ \\
\hline Gender & 5 males / 5 females & 7 males / 3 females \\
Age (years) & $67.6(2.4)$ & $68.1(2.9)$ \\
Body mass $(\mathrm{kg})$ & $66.3(11.3)$ & $68.0(12.0)$ \\
Height $(\mathrm{cm})$ & $162.5(8.6)$ & $164.9(9.2)$ \\
\hline
\end{tabular}

Values are group means (standard deviation).

risk factors ${ }^{2,3,13-16)}$

The decrease in walking ability due to reduced lower limb neuromuscular function is an important cause of falls in the elderly. With falls being a major cause of mortality in the elderly, and up to one-third of the elderly population experiencing at least one fall each year ${ }^{17,18}$, development of exercises and rehabilitation programs for the elderly could be an important preventive measure for reducing the incidence of falls.

Winter ${ }^{19)}$ described gait as a dynamic process for performing movements through high-level proprioceptive sense, neuromuscular adjustment, and coordination among body segments and joints. In other words, even if lower limb muscular strength is improved, poor coordination between segments can affect the ability to walk efficiently. He also reported that excessive variability in walking or improper coordination between segments and joints can also result in gait imbalance and falls.

Thus far, many gait-related studies in the elderly have used gait parameters or joint kinematics in designing interventions to prevent potential falls. It is, however, difficult to confirm enhancement in neuromuscular adjustment or coordination with these variables. Therefore, previous studies that examined the walking ability of elderly participants who had undergone rehabilitative Pilates exercise programs could not provide insight into the fundamental mechanism of falls or gait imbalance.

Inter-joint coordination is a method of investigating the coordination of two adjacent joints during walking. It is calculated through continuous relative phase (CRP) as the phase plane formed based on angle and angular velocity ${ }^{20)}$. Many researchers report that inter-joint coordination controls the body's center of mass and can be expressed as the ability to maintain dynamic balance ${ }^{20-22}$. Unlike the traditional end-point variability, which refers to the changes in each segment or joint movement, the variability of inter-joint coordination indicates the variation in the pattern of performed movements. Accordingly, the changes in the variability of inter-joint coordination are represented as inherent properties of neuromuscular control, which determines the risk of injuries such as falls ${ }^{23}$.

Therefore, the purpose of this study was to examine the effects of an 8-week modified Pilates exercise program on the variability of inter-joint coordination in the gait of elderly participants.

\section{SUBJECTS AND METHODS}

Twenty elderly participants were recruited for this study (Table 1). None of the participants had a history of orthopedic abnormalities within the past year. The selected participants were randomized into two groups of equal size- the Pilates exercise training group (TG) and the control group (CG). During the intervention period, the TG participated in Pilates exercise training and received regular treatment at a disabled rehabilitation center, while the CG received only regular treatment at the disabled rehabilitation center.

The study protocol was approved by the university's institutional review board prior to study commencement.

The Pilates exercise used in this study was a mat-based Pilates program. To ensure that elderly participants could perform the exercise adequately, the intensity was modified, and additional props such as balls, magic rings, and resistance bands were used. The program was conducted by two licensed Pilates instructors three times a week for 8 weeks. Each session lasted 60 minutes and comprised a warm-up exercise, the main exercise, and a cooldown exercise.

Eight sets were performed for each movement in this Pilates training. For improving core muscles stability, breathing exercises were conducted in a sitting posture before and after all training sessions. The mat-based Pilates training program was composed of spine mobility exercise, upper limb exercise, and lower limb strengthening exercise; the detailed movements for each part of the program were as follows: 1) for spine mobility exercise chin up and down and seated forward and side spine stretches with a TheraBand; 2) for upper limb exercise, draw a sword and seated detoid lifts with a TheraBand; and 3) for lower limb strengthening exercise, side-lying top- and bottom-leg pulse-downs with a magic circle and seated foot and ankle strengtheners with a TheraBand. Of note, unlike general mat-based Pilates training, the lower limb strengthening exercise included in this program helps to strengthen the quadriceps, gluteus medius, adductor magnus, gastrocnemius, and anterior tibialis.

A 3-D gait motion analysis with 8 infrared cameras was performed before and after the exercise period. Before the experiment, the cameras were set around a $10 \mathrm{~m}$ gait path for sufficient tracking redundancy and were calibrated using the nonlinear transformation method. To identify lower limb movement and calculate inter-joint coordination variability during 
walking, 16 reflective markers were attached to the lower body of the subjects. Bilateral markers were placed on the iliac crest, posterior superior iliac spine, and greater trochanter. Additional markers were placed on the sacrum, left lateral femoral epicondyles, lateral malleolus, heel, 3rd metatarsal, and 5th metatarsal. Finally, two markers were placed on the left lateral thigh and shank. After sufficient warm-up, each subject was asked to walk on the $10 \mathrm{~m}$ gait path at his or her preferred walking speed. Subjects' gait trials were captured into the host computer with 8 infrared cameras (Oqus 300, Sweden) and five strides from the middle of the gait path were recorded. Gait was captured at a sampling rate of $100 \mathrm{~Hz}$, and to reduce the random error from electronic devices, a Butterworth 4th order low-pass filter was used at a cutoff frequency of $6 \mathrm{~Hz}$.

To obtain the CRP, the angle and angular velocity of lower extremity joints were calculated. These variables were interpolated $100 \%$ such that $1 \%$ represented each moment of the gait ${ }^{24}$. Thereafter, to remove the differences in amplitude and frequency among joints and to prevent the loss of data when the angular velocity was 0 , the following two formulae were used to normalize the angle and angular velocity from 1 to $+1^{25,26)}$.

$$
\begin{aligned}
\theta_{i, \text { norm }} & =2 \times \frac{\theta_{i}-\min (\theta)}{\max (\theta)-\min (\theta)}-1, \\
\omega_{i, \text { norm }} & =\frac{\omega_{i}}{\max (|\omega|)},
\end{aligned}
$$

where, $\theta_{i, n o r m}$ and $\omega_{i, \text { norm }}$ represent the normalized angle and angular velocity at ith sample, respectively. Max and min represent max and min values during the analysis phase, respectively.

After setting the phase plane formed based on the normalized angle $(\theta)$ and angular velocity $(\omega)$, the phase angle $(\varnothing)$ of each joint within the range of $0-180^{\circ}$ was calculated using the right horizontal axis as the origin. The two segments to be checked for inter-joint coordination (i.e., the thigh and shank) were then selected, and the difference between the phase angles of the proximal and distal joints in each segment were used to calculate the CRP $\left(\varnothing_{\text {hip-knee }}, \varnothing_{\text {knee-ankle }}\right)$.

$$
\mathrm{CRP}_{i}=\left|\varnothing_{i, \text { proximal_segment }}-\varnothing_{i, \text { distal_segment }}\right|
$$

Finally, inter-joint coordination variability was evaluated by using the deviation phase (DP), which was a mean value of the standard deviation calculated from each data point of the CRP. To evaluate the variability in single-joint coordination, an identical method was used to calculate variability of angles of the ankle joint, knee joint, and hip joint in terms of the mean standard deviation.

To verify the effects of the Pilates exercise on the variability of inter-joint coordination in each subject's lower extremities, 2-way ANOVA with repeated measure was used. Bonferroni correction was used as a post hoc test, as required. For all tests in this study, statistical significance was set at $\alpha=0.05$.

\section{RESULTS}

There was a significant increase in the hip-knee DP value for the TG after the Pilates training had been completed. This increase was also significant when compared with that in the CG (Table 1, $\mathrm{p}<0.05$ ). However, there was no significant difference in the knee-ankle DP value (Table 2, $\mathrm{p}>0.05$ ).

There was no significant difference in the joint variability of the ankle, knee, and hip joints between the TG and CG, either before or after the intervention period (Table $3, \mathrm{p}>0.05$ ).

\section{DISCUSSION}

This study examined the influence of a modified Pilates training program on changes in the variability of inter-joint coordination during walking in elderly participants. The traditional concept of variability starts from "end-point variability." According to this concept, low variability indicates a stable performance while performing motions aimed at achieving certain movements. Arutyunyan et al. ${ }^{27)}$ and Hausdorff ${ }^{28)}$ reported that the gait of healthy adults tends to demonstrate lower variability than that of the elderly, and this is also true of performance of higher-level athletes compared to lower-level athletes. Accordingly, research on biomechanics and motor control has used this variability as a marker of performance level ${ }^{29,30)}$.

Unlike the variability described above, in the dynamic system theory, coordinative variability is considered diverse coordination patterns that appear while performing tasks rather than essentially good or bad of the performance ${ }^{31,32)}$, or is considered to present the adaptability required for adjusting movements ${ }^{22,33}$. Generally, increased coordinative variability is interpreted as enhanced adjustment of coordination patterns required for adapting to new movement patterns or maintaining particular movements $\left.{ }^{25}, 34\right)$. On the other hand, decreased coordinative variability can explain the causes of injuries or diseases that occur when the decrease in coordinative variability reaches a decisive point ${ }^{22,33)}$.

Arutyunyan et al. ${ }^{27)}$ reported that the performance of higher-level athletes indicates low variability and high coordinative variability compared with that of lower-level athletes and that this signifies that higher coordinative variability allows diverse coordination patterns among segments or joints for achieving particular movements. In addition, Seay et al. ${ }^{34)}$ emphasized the connection between the diversity of coordination patterns and risk of injuries in their report, as their "no injury history" group showed the highest coordinative variability, followed by their "injury history" group and then their "current injury" 
Table 2. Variability of inter-joint coordination of the training and control groups between exercise periods

\begin{tabular}{llll}
\hline & & \multicolumn{2}{c}{ Mean \pm SD } \\
\cline { 3 - 4 } & & TG $(\mathrm{n}=10)$ & CG $(\mathrm{n}=10)$ \\
\hline \multirow{2}{*}{ Hip-Knee DP $\left({ }^{\circ}\right)$} & Pre & $12.51 \pm 3.09$ & $12.26 \pm 4.06$ \\
& Post & $20.01 \pm 7.34$ ab & $11.66 \pm 6.61$ \\
Knee-Ankle DP & Pre & $23.26 \pm 13.25$ & $24.22 \pm 13.88$ \\
& Post & $24.77 \pm 5.91$ & $25.53 \pm 12.19$ \\
\hline
\end{tabular}

TG: modified Pilates training group; CG: control group. Values are shown as the group

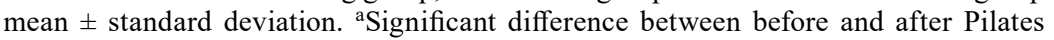
training. ${ }^{b}$ Significant difference between groups $(\mathrm{p}<0.05)$.

Table 3. Variability of lower extremity joint angular positions of the training and control groups between exercise periods

\begin{tabular}{llll}
\hline & & \multicolumn{2}{c}{ Mean \pm SD } \\
\cline { 3 - 4 } & & TG $(\mathrm{n}=10)$ & $\mathrm{CG}(\mathrm{n}=10)$ \\
\hline \multirow{2}{*}{ Hip SD $\left(^{\circ}\right)$} & Pre & $1.30 \pm 0.28$ & $1.50 \pm 0.75$ \\
& Post & $1.47 \pm 0.60$ & $1.50 \pm 0.80$ \\
\multirow{2}{*}{ Knee SD $\left({ }^{\circ}\right)$} & Pre & $1.94 \pm 0.42$ & $2.12 \pm 1.15$ \\
& Post & $2.24 \pm 0.68$ & $2.14 \pm 1.53$ \\
\multirow{2}{*}{ Ankle SD $\left(^{\circ}\right)$} & Pre & $1.08 \pm 0.20$ & $1.20 \pm 0.51$ \\
& Post & $1.33 \pm 0.24$ & $1.25 \pm 0.38$ \\
\hline
\end{tabular}

TG: modified Pilates training group; CG: control group

group.

In this study, there was no significant difference in lower extremity joint variability between the intervention and control groups (Table 3, p>0.05), but significantly increased hip-knee coordinative variability was found in the TG compared with the CG (Table 1, $\mathrm{p}<0.05$ ). Our results are consistent with previous studies on inter-joint coordination for preventing and reducing the risk of falls during walking in elderly participants ${ }^{35,36}$. These studies also reported that elderly participants had significantly reduced hip-knee coordinative variability compared with that of healthy adults and that the higher the hip-knee coordinative variability, the more neuromuscular control strategies were shown during walking.

In our study, the Pilates exercise group revealed an increase in hip-knee coordinative variability, while joint variability remained unchanged. This may be because the Pilates exercise developed the deep muscles, which may have helped to improve the flexibility of the pelvis and hip joints ${ }^{1-4,7}$. This also suggests that more diverse coordination patterns are gained while maintaining the variability of the joint angular position.

In conclusion, our study has demonstrated that an 8-week modified Pilates exercise program can have a positive impact on the gait of elderly participants, potentially by enhancing neuromuscular adjustment, which may have positive implications for reducing their fall risk.

\section{ACKNOWLEDGEMENT}

This research was supported by the Gachon University research fund of 2014 (GCU-2014-0132).

\section{REFERENCES}

1) Culligan PJ, Scherer J, Dyer K, et al.: A randomized clinical trial comparing pelvic floor muscle training to a Pilates exercise program for improving pelvic muscle strength. Int Urogynecol J Pelvic Floor Dysfunct, 2010, 21: 401-408. [Medline] [CrossRef]

2) Irez GB, Ozdemir RA, Evin R, et al.: Integrating pilates exercise into an exercise program for 65+ year-old women to reduce falls. J Sports Sci Med, 2011, 10: 105-111. [Medline]

3) Kloubec JA: Pilates for improvement of muscle endurance, flexibility, balance, and posture. J Strength Cond Res, 2010, 24: 661-667. [Medline] [CrossRef]

4) Phrompaet S, Paungmali A, Pirunsan U, et al.: Effects of pilates training on lumbo-pelvic stability and flexibility. Asian J Sports Med, 2011, 2: 16-22. [Medline] [CrossRef] 
5) Sekendiz B, Altun Ö, Korkusuz F, et al.: Effects of Pilates exercise on trunk strength, endurance and flexibility in sedentary adult females. J Bodyw Mov Ther, 2007, 11: 318-326. [CrossRef]

6) Critchley DJ, Pierson Z, Battersby G: Effect of pilates mat exercises and conventional exercise programmes on transversus abdominis and obliquus internus abdominis activity: pilot randomised trial. Man Ther, 2011, 16: 183-189. [Medline] [CrossRef]

7) Emery K, De Serres SJ, McMillan A, et al.: The effects of a Pilates training program on arm-trunk posture and movement. Clin Biomech (Bristol, Avon), 2010, 25: 124-130. [Medline] [CrossRef]

8) Franco YR, Liebano RE, Moura KF, et al.: Efficacy of the addition of interferential current to Pilates method in patients with low back pain: a protocol of a randomized controlled trial. BMC Musculoskelet Disord, 2014, 15: 420. [Medline] [CrossRef]

9) Miyamoto GC, Costa LO, Galvanin T, et al.: Efficacy of the addition of modified Pilates exercises to a minimal intervention in patients with chronic low back pain: a randomized controlled trial. Phys Ther, 2013, 93: 310-320. [Medline] [CrossRef]

10) Shea S, Moriello G: Feasibility and outcomes of a classical Pilates program on lower extremity strength, posture, balance, gait, and quality of life in someone with impairments due to a stroke. J Bodyw Mov Ther, 2014, 18: 332-360. [Medline] [CrossRef]

11) Surbala L, Khuman PR, Gopal Nambi S, et al.: Pilates in functional balance and quality of life in sub-acute stroke subjects - a randomized controlled study. Int J Health Rehab Sci, 2013, 2: 204-211.

12) Bird ML, Fell J: Positive long-term effects of Pilates exercise on the aged-related decline in balance and strength in older, community-dwelling men and women. J Aging Phys Act, 2014, 22: 342-347. [Medline] [CrossRef]

13) Siqueira Rodrigues BG, Ali Cader S, Bento Torres NV, et al.: Pilates method in personal autonomy, static balance and quality of life of elderly females. J Bodyw Mov Ther, 2010, 14: 195-202. [Medline] [CrossRef]

14) Hyun J, Hwangbo K, Lee CW: The effects of pilates mat exercise on the balance ability of elderly females. J Phys Ther Sci, 2014, 26: 291-293. [Medline] [CrossRef]

15) Mokhtari M, Nezakatalhossaini M, Esfarjani F: The effect of 12-week pilates exercises on depression and balance associated with falling in the elderly. Procedia Soc Behav Sci, 2013, 70: 1714-1723. [CrossRef]

16) Newell D, Shead V, Sloane L: Changes in gait and balance parameters in elderly subjects attending an 8-week supervised Pilates programme. J Bodyw Mov Ther, 2012, 16: 549-554. [Medline] [CrossRef]

17) Hartholt KA, van Beeck EF, Polinder S, et al.: Societal consequences of falls in the older population: injuries, healthcare costs, and long-term reduced quality of life. J Trauma, 2011, 71: 748-753. [Medline] [CrossRef]

18) Rubenstein LZ: Falls in older people: epidemiology, risk factors and strategies for prevention. Age Ageing, 2006, 35: ii37-ii41. [Medline] [CrossRef]

19) Winter DA: Foot trajectory in human gait: a precise and multifactorial motor control task. Phys Ther, 1992, 72: 45-53, discussion 54-56. [Medline]

20) Lacquaniti F, Maioli C, Borghese NA, et al.: Posture and movement: coordination and control. Arch Ital Biol, 1997, 135: 353-367. [Medline]

21) Hamill J, Palmer C, Van Emmerik RE: Coordinative variability and overuse injury. Sports Med Arthrosc Rehabil Ther Technol, 2012, 4: 45. [Medline] [CrossRef]

22) Harbourne RT, Stergiou N: Movement variability and the use of nonlinear tools: principles to guide physical therapist practice. Phys Ther, 2009 , $89: 267-282$. [Medline] [CrossRef]

23) Hamill J, van Emmerik RE, Heiderscheit BC, et al.: A dynamical systems approach to lower extremity running injuries. Clin Biomech (Bristol, Avon), 1999, 14: 297-308. [Medline] [CrossRef]

24) Pollard CD, Heiderscheit BC, van Emmerik RE, et al.: Gender differences in lower extremity coupling variability during an unanticipated cutting maneuver. J Appl Biomech, 2005, 21: 143-152. [Medline] [CrossRef]

25) Hamill J, Haddad JM, McDermott WJ: Issues in quantifying variability from a dynamical systems perpective. J Appl Biomech, 2000, 16: 407-418. [CrossRef]

26) Miller RH, Meardon SA, Derrick TR, et al.: Continuous relative phase variability during an exhaustive run in runners with a history of iliotibial band syndrome. J Appl Biomech, 2008, 24: 262-270. [Medline] [CrossRef]

27) Arutyunyan GH, Gurfinkel VS, Mirskii ML: Organization of movements on execution by man of an exact postural task. Biophysics (Oxf), 1969, 14: 1162-1167.

28) Hausdorff JM: Gait dynamics, fractals and falls: finding meaning in the stride-to-stride fluctuations of human walking. Hum Mov Sci, 2007, 26: 555-589. [Medline] [CrossRef]

29) Fitts PM: The information capacity of the human motor system in controlling the amplitude of movement. J Exp Psychol, 1954, 47: 381-391. [Medline] [CrossRef]

30) Schmidt RA, Zelaznik H, Hawkins B, et al.: Motor-output variability: a theory for the accuracy of rapid motor acts. Psychol Rev, 1979, 47: 415-451. [Medline] [CrossRef]

31) Haken H, Kelso JA, Bunz H: A theoretical model of phase transitions in human hand movements. Biol Cybern, 1985, 51: 347-356. [Medline] [CrossRef]

32) Schöner G, Kelso JA: Dynamic pattern generation in behavioral and neural systems. Science, 1988, 239: 1513-1520. [Medline] [CrossRef]

33) Scholz JP: Dynamic pattern theory—some implications for therapeutics. Phys Ther, 1990, 70: 827-843. [Medline]

34) Seay JF, Haddad JM, van Emmerik RE, et al.: Coordination variability around the walk to run transition during human locomotion. Mot Contr, 2006, 10: 178-196. [Medline] [CrossRef]

35) Buzzi UH, Stergiou N, Kurz MJ, et al.: Nonlinear dynamics indicates aging affects variability during gait. Clin Biomech (Bristol, Avon), 2003, 18: 435-443. [Medline] [CrossRef]

36) Chiu SL, Chou LS: Effect of walking speed on inter-joint coordination differs between young and elderly adults. J Biomech, 2012, 45: 275-280. [Medline] [CrossRef] 